\title{
Introduction to part two: the capitalist state
}

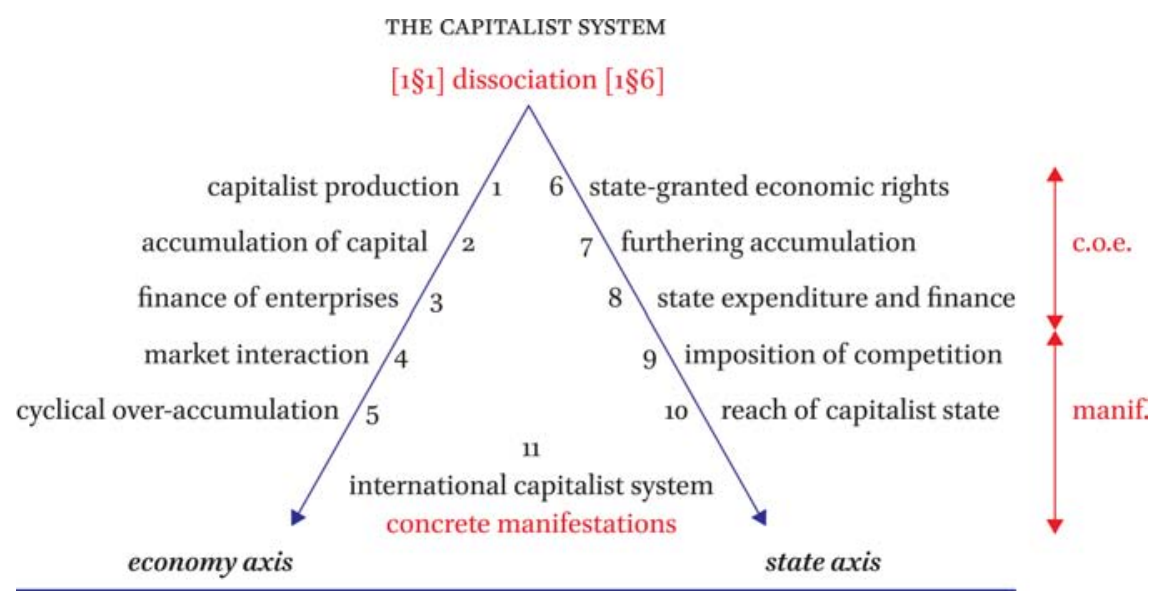

Note: 'c.o.e.' abbreviates conditions of existence and 'manif.' concrete manifestations.

Part Two of this book presents the state and economic policy (Chapters 6-10) vis-à-vis the capitalist economy (Chapters 1-5). Part One sought to ground the capitalist economy 'within itself'. In Part Two, we will see why and how these grounds are insufficient. Early on in Chapter 6 it is shown that the capitalist economy's existence necessarily requires the capitalist state $\left(6 \mathrm{D}_{2}\right.$ will clarify why the term 'capitalist' state is used at all). The exposition will then be confronted with a twofold task. It must show how the state's doing and not doing can provide sufficient grounds for the economy's existence. However, along with it, the conditions for the existence of the state itself must be presented. Recall from the General Introduction the following schematic outline.

The starting point of Chapter 6 is similar to that of Chapter 1: the dissociated bifurcation between households and privately owned enterprises. Inasmuch as Chapters 1-3 next sought its economy-immanent conditions of existence, Chapters 6-8 will seek sufficient conditions of existence for the economy as well as for the state itself. A similar analogy applies to the last two chapters of this Part: Chapters 9-10 will present the concrete manifestations of the state vis-à-vis the economy.

The order of the book is evidently as it is: from Chapters 1-11. This is in line with one object of the book - as indicated in the General Introduction - which is that Part One endeavours to show to what extent the capitalist economy might be thought to conceivably stand on itself. In line with this, the systematic exposition runs from Chapters 1-5 and again Chapters 6-10.

(C) GEERT REUTEN, 2019 | DOI:10.1163/9789004392809_008

This is an open access chapter distributed under the terms of the prevailing CC-BY-NC-ND License at the time of publication. 
However, the book also sets out a complementary systematic, which runs zigzag from Chapter 1 to the juxtaposed 6, and from Chapter 2 to the juxtaposed 7, and so forth. In principle the book might be read in that order. This last systematic mainly determines the dividing lines between the chapters of Part Two.

As before, the exposition is a systematic one, not a historical one. Therefore the abstract existence of the capitalist state is presumed. Systematically this presumption refers indeed to an abstract existence, that is, as long as its conditions of existence have not yet been presented.

Finally, when I use the term 'state' this includes, when relevant, the central state of a federation or of a union of states. 